\title{
Development of a preoperative predictive model for major complications following adult spinal deformity surgery
}

\author{
Justin K. Scheer, MD, ${ }^{1}$ Justin S. Smith, MD, PhD, ${ }^{2}$ Frank Schwab, MD, ${ }^{3}$ Virginie Lafage, $\mathrm{PhD},{ }^{3}$ \\ Christopher I. Shaffrey, MD, ${ }^{2}$ Shay Bess, MD, ${ }^{4}$ Alan H. Daniels, MD, ${ }^{5}$ Robert A. Hart, MD, ${ }^{6}$ \\ Themistocles S. Protopsaltis, MD, ${ }^{4}$ Gregory M. Mundis Jr., MD, ${ }^{7}$ Daniel M. Sciubba, MD, ${ }^{8}$ \\ Tamir Ailon, MD, ${ }^{2}$ Douglas C. Burton, MD, ${ }^{9}$ Eric Klineberg, MD, ${ }^{10}$ Christopher P. Ames, MD, ${ }^{11}$ and \\ the International Spine Study Group
}

\begin{abstract}
${ }^{1}$ School of Medicine, University of California, San Diego, La Jolla, California; '2Department of Neurosurgery, University of Virginia Health System, Charlottesville, Virginia; ${ }^{3}$ Spine Service, Hospital for Special Surgery, New York; ${ }^{4}$ Department of Orthopaedic Surgery, NYU Hospital for Joint Diseases, New York, New York; ${ }^{5}$ Department of Orthopaedic Surgery, Brown University, Providence, Rhode Island; ${ }^{6}$ Department of Orthopaedic Surgery, Oregon Health \& Science University, Portland, Oregon; ${ }^{7}$ Scripps Health, La Jolla, California; ${ }^{8}$ Department of Neurosurgery, The Johns Hopkins Hospital, Baltimore, Maryland; ' Department of Orthopaedic Surgery, University of Kansas Medical Center, Kansas City, Kansas; ${ }^{10}$ Department of Orthopaedic Surgery, University of California, Davis; and ${ }^{11}$ Department of Neurological Surgery, University of California, San Francisco, California
\end{abstract}

OBJECTIVE The operative management of patients with adult spinal deformity (ASD) has a high complication rate and it remains unknown whether baseline patient characteristics and surgical variables can predict early complications (intraoperative and perioperative [within 6 weeks]). The development of an accurate preoperative predictive model can aid in patient counseling, shared decision making, and improved surgical planning. The purpose of this study was to develop a model based on baseline demographic, radiographic, and surgical factors that can predict if patients will sustain an intraoperative or perioperative major complication.

METHODS This study was a retrospective analysis of a prospective, multicenter ASD database. The inclusion criteria were age $\geq 18$ years and the presence of ASD. In total, 45 variables were used in the initial training of the model including demographic data, comorbidities, modifiable surgical variables, baseline health-related quality of life, and coronal and sagittal radiographic parameters. Patients were grouped as either having at least 1 major intraoperative or perioperative complication (COMP group) or not (NOCOMP group). An ensemble of decision trees was constructed utilizing the C5.0 algorithm with 5 different bootstrapped models. Internal validation was accomplished via a 70/30 data split for training and testing each model, respectively. Overall accuracy, the area under the receiver operating characteristic (AUROC) curve, and predictor importance were calculated.

RESULTS Five hundred fifty-seven patients were included: 409 (73.4\%) in the NOCOMP group, and $148(26.6 \%)$ in the COMP group. The overall model accuracy was $87.6 \%$ correct with an AUROC curve of 0.89 indicating a very good model fit. Twenty variables were determined to be the top predictors (importance $\geq 0.90$ as determined by the model) and included (in decreasing importance): age, leg pain, Oswestry Disability Index, number of decompression levels, number of interbody fusion levels, Physical Component Summary of the SF-36, Scoliosis Research Society (SRS)-Schwab coronal curve type, Charlson Comorbidity Index, SRS activity, T-1 pelvic angle, American Society of Anesthesiologists grade, presence of osteoporosis, pelvic tilt, sagittal vertical axis, primary versus revision surgery, SRS pain, SRS total, use of bone morphogenetic protein, use of iliac crest graft, and pelvic incidence-lumbar lordosis mismatch.

CONCLUSIONS A successful model (87\% accuracy, 0.89 AUROC curve) was built predicting major intraoperative or

\begin{abstract}
ABBREVIATIONS ANN = artificial neural network; $A S A=$ American Society of Anesthesiologists; $A S D=$ adult spinal deformity; $A U R O C=$ area under the receiver operating characteristic; $\mathrm{BMI}=$ body mass index; $\mathrm{BMP}=$ bone morphogenetic protein; $\mathrm{CCl}=$ Charlson Comorbidity Index; $\mathrm{HRQOL}=$ health-related quality of life; $\mathrm{MCS}=\mathrm{Mental}$ Component Summary of the SF-36; NRS = numeric rating scale; ODI = Oswestry Disability Index; PCS = Physical Component Summary of the SF-36; PI-LL = pelvic incidence-lumbar lordosis mismatch; PT = pelvic tilt; SRS = Scoliosis Research Society; SRS-22r = SRS-22r questionnaire; SVA = sagittal vertical axis; TK = thoracic kyphosis; T1PA = T-1 pelvic angle.
\end{abstract}

SUBMITTED February 13, 2016. ACCEPTED October 20, 2016.

INCLUDE WHEN CITING Published online March 24, 2017; DOI: 10.3171/2016.10.SPINE16197. 


\begin{abstract}
perioperative complications following ASD surgery. This model can provide the foundation toward improved education and point-of-care decision making for patients undergoing ASD surgery.

https://thejns.org/doi/abs/10.3171/2016.10.SPINE16197
\end{abstract}

KEY WORDS complications; adult spinal deformity; ASD; predictive modeling; scoliosis; sagittal malalignment; decision tree

$\mathrm{T}$ HE surgical management of adult spinal deformity (ASD) can provide significant improvements in pain, disability, and health-related quality of life (HRQOL). ${ }^{6,728,34,36-38,40-45}$ However, these procedures are technically demanding and are associated with a high complication rate. The patient population suitable for these complicated surgeries continues to increase, including patients of advanced age. ${ }^{2,16,17,27}$ The reported complication rates in the literature are varied and range from $14 \%$ to $71 \% .^{11,13,39,47,48}$ It has been demonstrated that complication rates increase for patients undergoing revision surgery, ${ }^{13} 3$-column osteotomies, ${ }^{8,23,30,49,50}$ and those of older age., ${ }^{2,16,20,39}$ Despite the abundant literature characterizing complication rates and the types of complications in ASD surgery, ${ }^{47,48}$ there is currently no model to predict which patients may develop complications following the surgical correction of ASD.

The ability to accurately identify these patients preoperatively constitutes a significant challenge, yet an accurate predictive model could be beneficial for both the patient and surgeon. The results of such a model could aid in the discussion between the patient and surgeon of whether to pursue a surgical intervention and, for those who opt for surgery, in adjusting the goals of surgery within the context of potential complication development. Additionally, the surgeon can plan accordingly for the operation and may employ additional techniques and/or preventative measures to potentially reduce the risk of the patient developing these complications. This patient-specific approach at complication avoidance could reduce the overall complication rate and thus potentially decrease patient morbidity.

With the advent of modern advanced predictive analytics techniques, one can now create accurate, patientspecific, predictive models with high accuracy, which can provide very useful information to aid in clinical decision making. ${ }^{15}$ Although traditional statistical methods can also be very clinically useful, these methods tend to be limited for use in developing patient-specific predictive models. ${ }^{1}$ Furthermore, they are generally designed to test specific hypotheses, have many assumptions that need to be satisfied before use, and use patient group means, not accounting for individual changes. ${ }^{1,32}$ Modern predictive modeling algorithms are very different because they can identify patterns in the data, allowing for accurate predictions without the need for a hypothesis. Thus, patientspecific models can be developed to provide valuable, detailed information, which can then be applied when discussing the risks of surgery with a patient. The goal of this study was to develop a model based on baseline demographic, radiographic, and surgical factors that could predict the patients likely to sustain a major intraoperative or perioperative complication.

\section{Methods \\ Patient Population}

This study is a retrospective review of a prospective multicenter ASD database, which is composed of patients from 11 sites across the US. All patients were enrolled in an IRB-approved protocol by each site. Inclusion criteria for the databases were age $\geq 18$ years and the presence of spinal deformity, as defined by any coronal Cobb angle $\geq$ $20^{\circ}$, sagittal vertical axis (SVA) $\geq 5 \mathrm{~cm}$, pelvic tilt $(\mathrm{PT}) \geq$ $25^{\circ}$, or thoracic kyphosis $(\mathrm{TK}) \geq 60^{\circ}$. Exclusion criteria included spinal deformity of a neuromuscular etiology and presence of active infection or malignancy.

\section{Data Collection, Radiographic Assessment, and HRQOL}

The demographic and clinical data collected included patient age, sex, body mass index (BMI), number of comorbidities, Charlson Comorbidity Index $(\mathrm{CCI}),{ }^{10}$ preoperative anemia, history of depression, osteoporosis, American Society of Anesthesiologists (ASA) physical status classification, as well as all intraoperative and perioperative complications. Surgical data collected included primary versus revision surgery, single versus staged procedures, posterior fusion rod diameter and material, the uppermost instrumented vertebra, the lowermost instrumented vertebra, use of direct spinal decompression, number of decompression levels, number of Smith-Petersen osteotomies, presence of a 3-column osteotomy (pedicle subtraction osteotomy or vertebral column resection), number of interbody fusions, use of an iliac graft, use of recombinant human bone morphogenetic protein (BMP), and number of posterior vertebral levels fused. The surgical variables were included under the assumption that the same factors could be derived from a preoperative surgical plan and that their inclusion would yield a more complete preoperative predictive model.

Full-length (36-inch cassette) posteroanterior and lateral spine radiographs at baseline and 6 weeks follow-up were analyzed using validated software ${ }^{9,33}$ (SpineView, ENSAM, Laboratory of Biomechanics). Only baseline radiographic measures were included in the model and the 6-week radiographs were used for complication determination. All radiographic measures were performed at a central location based on standard techniques ${ }^{31}$ and included: maximum coronal Cobb angles of thoracic and lumbar curves (grouped by $<30^{\circ}, 30^{\circ}-60^{\circ}$, and $>60^{\circ}$ ); coronal C-7 plumb line; TK (T4-12; Cobb angle between superior endplate of T-4 and inferior endplate of T-12); lumbar lordosis (Cobb angle between superior endplate of L-1 and superior endplate of S-1); SVA (offset of C-7 plumb line relative to $\mathrm{S}-1$ ); PT; the mismatch between pelvic incidence and lumbar lordosis (PI-LL); and the T-1 pelvic angle (T1PA; the angle between the line from the 
femoral head axis to the centroid of T-1 and the line from the femoral head axis to the middle of the $S-1$ endplate). Based on the above radiographic parameters, patients were additionally stratified by the SRS-Schwab ASD classification. ${ }^{35}$

Standardized HRQOL measures were recorded at baseline and included the Oswestry Disability Index (ODI), SF-36, and Scoliosis Research Society-22r questionnaire (SRS-22r). Two standard summary scores were calculated based on the SF-36, the Physical Component Summary (PCS) and the Mental Component Summary (MCS). The SRS-22r provides a total score and multiple subdomains, including activity, pain, appearance, mental, and satisfaction. A numeric rating scale (NRS) score ranging from 0 (no pain) to 10 (most unbearable pain) was collected for back and leg pain separately.

Patients were grouped as either having at least $1 \mathrm{ma}-$ jor intraoperative or perioperative complication (COMP group) or not (NOCOMP group). Perioperative complications were defined as those occurring within 6 weeks of surgery. Major and minor complications were classified according to the study of Glassman et al. ${ }^{18}$ All of the patients included had a minimum of 6 weeks of follow-up to capture any perioperative complications. The complication categories included cardiopulmonary, electrolyte, gastrointestinal, implant, infection, musculoskeletal, neurological, operative, radiographic, renal, vascular, wound, and other.

\section{Statistical Analysis and Predictive Model Construction}

Continuous variables were described with means and standard deviations. Baseline variables were compared between the groups. Normality of data was determined using the Shapiro-Wilk test. Comparison of baseline means between the groups included the Student t-test or Wilcoxon rank-sum tests where appropriate. Frequency analyses for categorical variables were conducted via Pearson's $\chi^{2}$ analysis. All statistical analyses were conducted using commercially available software (SPSS version 22, IBM Inc.) and the level of significance was set at $p<0.05$ for all tests.

For the predictive model, missing values within the database were imputed using standard techniques such as mean and median imputation. ${ }^{1}$ Once a complete data set was constructed, an ensemble of decision trees was constructed with a binary target variable that included patients who sustained at least 1 major intraoperative or perioperative complication, as defined above (code $=1$ ), or not having any major intraoperative or perioperative complications $($ code $=0$ ). The decision-tree algorithm was C5.0 and 5 different bootstrapped models were built. ${ }^{1}$ Internal validation was accomplished via a 70/30 data split for training and testing the model, respectively. ${ }^{1}$ Final overall predictions from the models were combined and chosen by voting with random selection for tied votes. Overall accuracy and the area under the receiver operating characteristic (AUROC) curve were calculated as well as predictor importance as determined by the model. The model was built using commercially available software (SPSS Modeler version 16, IBM Inc.).

\section{Results}

\section{Patient Population}

A total of 557 operative patients were available and included in the study. Of those, 409 did not sustain a major complication (NOCOMP group, 73.4\%), and 148 had at least 1 intraoperative or perioperative major complication (COMP group, 26.6\%). From the total, 390 patients (70\%) were used for model training and $167(30 \%)$ for testing the model. The percentage split was determined randomly but was within the acceptable splitting percentage options for predictive modeling. ${ }^{1}$ There were 439 women $(78.8 \%)$ and 118 men $(21.2 \%)$ and the mean age was $57.5 \pm 15.3$ years with a mean BMI of $27.6 \pm 8.6 \mathrm{~kg} / \mathrm{m}^{2}$ (Table 1). The COMP group was significantly older, had a greater mean BMI, higher mean CCI, higher mean ASA score, and a higher proportion of patients with osteoporosis $(\mathrm{p}<0.05$ for all, Table 1). The COMP group had a significantly higher proportion of patients with baseline SRS-Schwab coronal curve type of $\mathrm{L}(47.6 \%$ vs $30.8 \%, \mathrm{p}<0.05$, Table 1$)$.

\section{Surgical Data}

The COMP group had a larger proportion of patients who underwent a revision $(41.9 \%)$ versus primary surgery $(31.5 \% ; \mathrm{p}=0.023)$ and who had a direct decompression ( $25.7 \%$ vs $20.3 \%, p=0.0034$; Table 2 ). In addition, the COMP group had a significantly higher proportion of patients who underwent an interbody fusion, iliac crest graft, and BMP use ( $<0.05$ for all, Table 2). The mean number of posterior levels fused was statistically similar between groups ( $p>0.05$, Table 2). Both groups also had

TABLE 1. Demographic data of all the patients as well as each group

\begin{tabular}{|c|c|c|c|c|}
\hline Variable & All Patients & COMP & NOCOMP & $p$ Value \\
\hline No. of patients & 557 & 148 & 409 & \\
\hline Mean age \pm SD (yrs) & $57.5 \pm 15.3$ & $61.5 \pm 12.3$ & $56 \pm 16.1$ & 0.0004 \\
\hline Females/males & $439 / 118$ & $119 / 29$ & $320 / 89$ & 0.5806 \\
\hline Mean BMI \pm SD & $27.6 \pm 8.6$ & $28.6 \pm 6$ & $27.3 \pm 9.3$ & 0.0013 \\
\hline Mean $\mathrm{CCl} \pm \mathrm{SD}$ & $1.5 \pm 1.7$ & $1.9 \pm 1.7$ & $1.4 \pm 1.6$ & 0.0009 \\
\hline $\begin{array}{l}\text { Mean ASA score } \\
\quad \pm \text { SD }\end{array}$ & $2.3 \pm 0.7$ & $2.4 \pm 0.6$ & $2.3 \pm 0.7$ & 0.0061 \\
\hline Preop anemia (\%) & $52(9.3)$ & $12(8.1)$ & $40(9.8)$ & 0.5491 \\
\hline Osteoporosis (\%) & $70(12.6)$ & $28(18.9)$ & $42(10.3)$ & 0.0065 \\
\hline Depression (\%) & $131(23.5)$ & $35(23.6)$ & $96(23.5)$ & 0.9653 \\
\hline $\begin{array}{l}\text { SRS-Schwab coro- } \\
\text { nal curve type (\%) }\end{array}$ & & & & 0.0047 \\
\hline $\mathrm{N}$ & 33.6 & 30.3 & 34.8 & \\
\hline $\mathrm{T}$ & 5.9 & 4.8 & 6.3 & \\
\hline L & 35.3 & 47.6 & 30.8 & \\
\hline D & 25.1 & 17.2 & 28.0 & \\
\hline
\end{tabular}

SRS-Schwab coronal curve types: $\mathrm{N}=$ patients with no coronal curve $>30^{\circ}$ (i.e., no major coronal deformity); $\mathrm{T}=$ patients with a thoracic major curve > $30^{\circ}$ (apical level of T-9 or higher); $\mathrm{L}=$ patients with a lumbar or thoracolumbar major curve $>30^{\circ}$ (apical level of T-10 or lower); and $\mathrm{D}=$ patients with a double major curve, with each curve $>30^{\circ}$.

Boldface type indicates statistically significant differences between the COMP and NOCOMP groups. 
TABLE 2. Surgical data of all the patients as well as each group

\begin{tabular}{|c|c|c|c|c|}
\hline Surgical Data & $\begin{array}{c}\text { All Patients } \\
(\%)\end{array}$ & $\begin{array}{l}\text { COMP } \\
(\%)\end{array}$ & $\begin{array}{l}\text { NOCOMP } \\
(\%)\end{array}$ & $\begin{array}{c}p \\
\text { Value }\end{array}$ \\
\hline No. of patients & 557 & 148 & 409 & \\
\hline Primary/revision & $366 / 191$ & $86 / 62$ & $280 / 129$ & 0.0230 \\
\hline $\begin{array}{l}\text { Mean no. of posterior } \\
\text { levels fused } \pm \text { SD }\end{array}$ & $11.2 \pm 4.2$ & $11.6 \pm 3.8$ & $11 \pm 4.4$ & 0.5383 \\
\hline Decompression & $343(61.6)$ & $106(71.6)$ & $237(57.9)$ & 0.0034 \\
\hline 3-column osteotomy & $121(21.7)$ & $38(25.7)$ & $83(20.3)$ & 0.1736 \\
\hline $\begin{array}{l}\text { Smith-Petersen } \\
\text { osteotomy }\end{array}$ & $291(52.2)$ & $81(54.7)$ & $210(51.3)$ & 0.4799 \\
\hline Interbody fusion & $332(59.6)$ & $105(70.9)$ & $227(55.5)$ & 0.0010 \\
\hline Iliac crest graft & $163(29.3)$ & $53(35.8)$ & $110(26.9)$ & 0.0411 \\
\hline BMP use & $356(63.9)$ & $105(70.9)$ & $251(61.4)$ & 0.0376 \\
\hline $\begin{array}{l}\text { Posterior rod diam- } \\
\text { eter in } \mathrm{mm}\end{array}$ & & & & 0.626 \\
\hline 4.5 & $2(0.4)$ & $0(0)$ & $2(0.5)$ & \\
\hline 5.5 & $360(64.6)$ & $91(61.5)$ & $269(65.8)$ & \\
\hline 6.0 & $66(11.8)$ & $19(12.8)$ & $47(11.5)$ & \\
\hline 6.35 & $129(23.1)$ & $38(25.7)$ & $91(22.2)$ & \\
\hline Posterior rod material & & & & 0.7519 \\
\hline Cobalt chromium & $340(61.0)$ & $92(62.2)$ & $248(60.6)$ & \\
\hline Stainless steel & $115(20.6)$ & 27 (18.2) & $88(21.5)$ & \\
\hline Titanium & $101(18.1)$ & $29(19.6)$ & $72(17.6)$ & \\
\hline Other & $1(0.2)$ & $0(0)$ & $1(0.2)$ & \\
\hline
\end{tabular}

Boldface type indicates statistically significant differences between the COMP and NOCOMP groups.

statistically similar proportions of patients with different rod diameters and materials ( $p>0.05$ for both, Table 2 ). The proportion of patients who suffered major complications and specific complication subtypes are presented in Table 3 .

\section{Radiographic Data}

Baseline radiographic parameters of the COMP and NOCOMP groups are shown in Table 4. The COMP group had significantly greater mean baseline SVA (77.7 $\mathrm{mm}$ vs $61.2 \mathrm{~mm}, \mathrm{p}=0.015)$ and T1PA $\left(25.0^{\circ}\right.$ vs $21.4^{\circ}, \mathrm{p}=$ 0.014 ) than the NOCOMP group ( $<<0.05$ for both). Both groups had similar baseline mean PT, PI-LL, TK, C-7 coronal plumb line, and proportion of patients in each of the maximum coronal Cobb angle groups ( $p>0.05$ for all).

\section{HRQOL Data}

The COMP group had significantly worse baseline mean scores for ODI, PCS, SRS activity, SRS pain, SRS total, and leg pain NRS ( $p<0.05$ for all, Table 5). All other HRQOL variables were statistically similar between the groups ( $p>0.05$ for all).

\section{Model Results}

The overall model accuracy was $87.6 \%$ correct with an AUROC of 0.89 indicating a very good model fit. In total, 20 variables were determined to be the top predic-
TABLE 3. Distribution of complication number and types for the COMP group

\begin{tabular}{cc}
\hline \multicolumn{1}{c}{ Variable } & Value $(\%)$ \\
\hline Total no. of patients & 148 \\
\hline No. of major complications & $117(79.1)$ \\
\hline 1 & $18(12.2)$ \\
\hline 2 & $7(4.7)$ \\
\hline 3 & $3(2)$ \\
\hline 4 & $3(2)$ \\
\hline 5 or more & \\
\hline Complication type & $34(23)$ \\
\hline Cardiopulmonary & $0(0)$ \\
\hline Electrolyte & $1(0.7)$ \\
\hline Gastrointestinal & $10(6.8)$ \\
\hline Implant & $23(15.5)$ \\
\hline Infection & $0(0)$ \\
\hline Musculoskeletal & $34(23)$ \\
\hline Neurological & $57(38.5)$ \\
\hline Operative & $1(0.7)$ \\
\hline Other & $11(7.4)$ \\
\hline Radiographic & $4(2.7)$ \\
\hline Renal & $0(0)$ \\
\hline Vascular & $7(4.7)$ \\
\hline Wound &
\end{tabular}

tors (importance $\geq 0.90$ out of $0-1$ as determined by the model) and included (in decreasing importance): age, leg pain NRS, ODI, number of levels decompressed, number of levels with an interbody fusion, PCS, SRS-Schwab coronal curve type, CCI, SRS activity, T1PA, ASA grade, presence of osteoporosis, PT, SVA, primary version revi-

TABLE 4. Preoperative radiographic data parameters included in the model for all patients and the COMP and NOCOMP groups

\begin{tabular}{lcccc}
\hline $\begin{array}{c}\text { Preop Radiographic } \\
\text { Parameter }\end{array}$ & $\begin{array}{c}\text { All } \\
\text { Patients }\end{array}$ & COMP & NOCOMP & $\begin{array}{c}\text { p } \\
\text { Value }\end{array}$ \\
\hline Mean PT \pm SD $\left(^{\circ}\right)$ & $23.3 \pm 10.7$ & $25.1 \pm 10.4$ & $22.7 \pm 10.7$ & 0.086 \\
\hline Mean PI-LL \pm SD $\left(^{\circ}\right)$ & $15.7 \pm 21$ & $18.5 \pm 20.9$ & $14.6 \pm 21$ & 0.0523 \\
\hline Mean TK \pm SD $\left(^{\circ}\right)$ & $35.2 \pm 19.1$ & $36.7 \pm 19.1$ & $34.7 \pm 19.1$ & 0.3538 \\
\hline $\begin{array}{l}\text { Mean SVA } \pm \text { SD } \\
(\mathrm{mm})\end{array}$ & $65.6 \pm 74.2$ & $77.7 \pm 73.6$ & $61.2 \pm 74$ & 0.0148 \\
\hline $\begin{array}{c}\text { Mean T1PA } \pm \text { SD }\left(^{\circ}\right) \\
\text { Mean C-7 coronal } \\
\text { plumb line } \pm \text { SD } \\
\text { (mm) }\end{array}$ & $35 \pm 33.1$ & $38 \pm 36.5$ & $33.9 \pm 31.8$ & 0.2349 \\
\hline $\begin{array}{c}\text { Max coronal Cobb } \\
\text { angle groups (\%) }\end{array}$ & & $25 \pm 13.3$ & $21.4 \pm 13.1$ & 0.0138 \\
\hline$<30^{\circ}$ & $211(37.9)$ & $51(34.5)$ & $160(39.1)$ & \\
\hline $30^{\circ}-60^{\circ}$ & $247(44.3)$ & $76(51.4)$ & $171(41.8)$ & \\
\hline$>60^{\circ}$ & $99(17.8)$ & $21(14.2)$ & $78(19.1)$ & \\
\hline
\end{tabular}

Boldface type indicates statistically significant differences between the COMP and NOCOMP groups. 
TABLE 5. HRQOL measures for all patients and the COMP and NOCOMP groups

\begin{tabular}{lccll}
\hline Preop HRQOL & All Patients* & COMP $^{*}$ & NOCOMP* $^{*}$ & p Value \\
\hline ODI & $44.5 \pm 18.6$ & $49 \pm 17.8$ & $42.9 \pm 18.6$ & 0.0007 \\
\hline PCS & $31.4 \pm 9.4$ & $29.3 \pm 8.5$ & $32.1 \pm 9.7$ & 0.0021 \\
\hline MCS & $45.2 \pm 13.2$ & $44.7 \pm 12.6$ & $45.4 \pm 13.4$ & 0.3787 \\
\hline SRS & & & & \\
\hline Activity & $2.9 \pm 0.9$ & $2.7 \pm 0.8$ & $2.9 \pm 0.9$ & 0.0068 \\
\hline Pain & $2.4 \pm 0.8$ & $2.3 \pm 0.9$ & $2.4 \pm 0.8$ & 0.0239 \\
\hline Appearance & $2.4 \pm 0.8$ & $2.3 \pm 0.7$ & $2.4 \pm 0.8$ & 0.183 \\
\hline Mental & $3.4 \pm 0.9$ & $3.4 \pm 0.9$ & $3.4 \pm 0.9$ & 0.9881 \\
\hline Satisfaction & $2.7 \pm 1.1$ & $2.6 \pm 1$ & $2.8 \pm 1.1$ & 0.1857 \\
\hline Total & $2.8 \pm 0.7$ & $2.7 \pm 0.6$ & $2.8 \pm 0.7$ & 0.0276 \\
\hline Back pain NRS & $7.2 \pm 2.2$ & $7.4 \pm 2.2$ & $7.2 \pm 2.2$ & 0.1086 \\
\hline Leg pain NRS & $4.5 \pm 3.2$ & $5.4 \pm 3.2$ & $4.2 \pm 3.2$ & 0.0002 \\
\hline Boldace typ indicates
\end{tabular}

Boldface type indicates statistically significant differences between the COMP and NOCOMP groups.

* Data presented as mean \pm standard deviation.

sion surgery, SRS pain, SRS total, use of BMP, use of iliac crest graft, and PI-LL (Table 6).

\section{Discussion}

In this investigation, a large cohort of patients with ASD who underwent surgical correction was used to construct an accurate, internally validated, patient-specific, preoperative predictive model for developing a major intra- or perioperative complication. The model is designed for preoperative use and thus the surgical variables were added retrospectively with the assumption that these could have been part of a preoperative surgical plan. This model sets the framework to create a website or ideally a mobile (i.e., tablet) application for calculating the risk of developing short-term major complications in real time as a pointof-care device. In this context, when formulating the surgical plan, and in discussion with the patient, alterations could be made to optimize the risk-benefit equation. For example, a particular maneuver that may be appropriate in one patient with an otherwise low risk profile may, in a different patient with a high predicted baseline risk, be judged to be too dangerous. Quantifying surgical risk in a given patient represents a significant challenge given the multitude of factors that interact in a complex manner to contribute to the overall risk. The model presented herein could be readily applied to this task and yield objective and accurate information to aid surgeons and inform patients.

It is important to understand the rationale behind the predictive modeling technique used in the present study. Decision trees were chosen based on many desirable properties for the given binary outcome of having a complication or not that included: 1) ability to handle hundreds of variables, both categorical and continuous; 2) feasibility with missing data; and 3) ease of construction. ${ }^{1}$ The combination of 5 decision-tree models is termed an "ensemble" in which the final predictions are based on all 5 models. This allows for increased accuracy at the cost of decrease
TABLE 6. Variables used in the predictive model

\begin{tabular}{|c|c|}
\hline Sex & Interbody fusion (yes/no) \\
\hline (7) SRS-Schwab coronal curve type & (5) No. of interbody fusion levels \\
\hline (1) Age & (19) Iliac crest graft (yes/no) \\
\hline BMI & (18) BMP (yes/no) \\
\hline (15) Revision surgery (yes/no) & $\begin{array}{l}\text { Max Cobb angle }\left(<30^{\circ}, 30^{\circ}-\right. \\
\left.60^{\circ},>60^{\circ}\right)\end{array}$ \\
\hline At least 1 comorbidity (yes/no) & Coronal C-7 plumb line distance \\
\hline No. of comorbidities & (13) PT \\
\hline (8) $\mathrm{CCl}$ & (20) PI-LL \\
\hline Anemia (yes/no) & TK (T2-12) \\
\hline Depression (yes/no) & (14) C-7 SVA \\
\hline (12) Osteoporosis (yes/no) & (10) T1PA \\
\hline Staged surgery (yes/no) & (3) ODI \\
\hline (11) ASA grade & (6) SF-36 PCS \\
\hline Rod diameter & SF-36 MCS \\
\hline Rod material & (9) SRS activity \\
\hline Uppermost instrumented vertebra & (16) SRS pain \\
\hline Lowermost instrumented vertebra & SRS appearance \\
\hline No. of posterior levels fused & SRS mental \\
\hline Decompression (yes/no) & SRS satisfaction \\
\hline (4) No. of decompression levels & (17) SRS total \\
\hline Smith-Petersen osteotomy (yes/no) & Back pain NRS \\
\hline No. of Smith-Petersen osteotomies & (2) Leg pain NRS \\
\hline $\begin{array}{l}\text { 3-column osteotomy PSO/VCR } \\
\text { (yes/no) }\end{array}$ & \\
\hline
\end{tabular}

$\mathrm{PSO}=$ pedicle subtraction osteotomy; $\mathrm{VCR}$ = vertebral column resection.

The top 20 variables in terms of predictive value are numbered in parentheses.

in interpretability (transparency). ${ }^{1}$ The exact rules governing how the predictions are made are unavailable because the computer calculates all of the predictions, in contrast to logistic regression, in which one obtains odds/hazard ratios to apply. Internal validation of the model was accomplished by splitting the data in a 70/30 ratio for training and testing, respectively, to increase the generalizability of the model. Both data sets were randomly chosen with the training set used for model construction and the testing data set used to determine the accuracy (and AUROC) as those patients were not involved in the model building. And the final modeling principle involved bootstrapping the data sets (as well as each of the 5 decision trees), which results in no model receiving the same set of patient data. This greatly increases the generalizability of the final model.

It is important to note that the predictive modeling techniques used in the present study, as well as in general, are a distinct form of analysis compared with traditional regression in several ways. ${ }^{1}$ It involves complex algorithms that identify patterns in large data sets, which then allow for prediction of a given outcome of interest. There was no hypothesis, no control being compared, and the model relied entirely on the available data. ${ }^{1}$ Conversely, traditional statistics are mathematical analyses used to test a hypothesis about a relationship between independent and dependent variables, and thus appropriate controls are necessary. Furthermore, the appropriate statistical test must be 
selected for a given clinical question/hypothesis and type of data. Using the wrong statistical test can result in erroneous results. Predictive modeling is more flexible due to the fact that it relies on the available data. Decision trees were used in this setting because of the advantages stated above, not because of the type of data and not because of a certain hypothesis. Additionally, multiple types of models can be constructed to assess which one has the greatest utility for the aims of the model, hence the ensemble of decision trees that was used. ${ }^{1}$ One can combine models that are similar (or different) to further enhance the goals of the model. ${ }^{1}$ When creating a model one must balance accuracy, generalizability, and transparency. ${ }^{1}$ We have created a model that is accurate and theoretically generalizable, yet not transparent. The type of model being built, and the balance of the 3 primary characteristics, depends on how it will be used when deployed in clinical practice.

There are few predictive models reported in the spine literature that Osorio et al. has identified, ${ }^{32}$ and for the ones that do exist, logistic regression is a popular technique that produces sets of odds ratios for developing the outcome of interest. ${ }^{12,21,24,29,46}$ Logistic regression is commonly used in prediction analysis because it is simple, easy to interpret and apply, and transparent. ${ }^{1}$ Chapman and colleagues consolidated a number of logistic regression models for complications following "spine surgery" from 6 different peer-reviewed papers into a web-based predictive model. $5,14,19,22,25,26$ This was an impressive feat, but in contrast to the decision trees used in the present study, there are specific limitations to logistic regression. There are a number of assumptions that must be satisfied to apply logistic regression as mentioned above and they generally identify variables that are "predictors" without a patient-specific interpretation. Our predictive model was constructed in 1 setting as opposed to 6 different studies with all the variables in 1 database. It is more efficient, updated with current predictive algorithms, is patient specific, and applies directly to patients with ASD.

Similar to our methodology, Daubs and colleagues performed a decision-tree analysis and used an ensemble of 50 decision trees to predict psychological distress in spine patients. ${ }^{15}$ Their model was very successful using 6 variables and 188 patients, as it was 92\% accurate, 92\% sensitive, and $95 \%$ specific. ${ }^{15}$ And lastly, one of the more advanced predictive modeling techniques was deployed by Azimi and colleagues in which they created an artificial neural network (ANN) to predict 2-year surgical satisfaction in surgical patients for lumbar spinal canal stenosis undergoing surgery. ${ }^{3}$ They compared the ANN to logistic regression and found that the use of ANN was more accurate than the logistic regression model. These types of studies, in addition to ours, represent the beginning of the use of predictive analytics in spine surgery outcomes. ${ }^{4}$ As data sets get larger with time and the quality of the data increases, advanced predictive analytics will likely play a larger role in clinical decision making.

The strengths of the current study include the multicenter design and a large number of patients with ASD (n $=557$ ). The multicenter design (11 different sites across the US) allows for better generalizability of the results. Another strength of this study is the complete preoperative and 6-week follow-up of the patients as well as the use of 45 variables. And lastly, modern predictive analytics algorithms were used to create the model, providing a patientspecific decision-tree ensemble.

However, there are a few limitations to this study, one of which includes the retrospective design that may have introduced selection or information biases. Another limitation includes combining both intra- and perioperative complications as the target variable of interest. Ideally, with greater numbers of patients, these intraoperative and perioperative complications would be separated out. This model is one of the first of its kind and sets the groundwork for advanced predictive analytics in spinal outcomes research.

\section{Conclusions}

A successful model (87\% accuracy, 0.89 AUROC) was built predicting major intra- or perioperative complications. This model can provide the foundation toward improved education and point-of-care decision making for patients undergoing ASD surgery.

\section{References}

1. Abbott D: Applied Predictive Analytics: Principles and Techniques for the Professional Data Analyst. Indianapolis: Wiley, 2014

2. Acosta FL Jr, McClendon J Jr, O’Shaughnessy BA, Koller H, Neal CJ, Meier O, et al: Morbidity and mortality after spinal deformity surgery in patients 75 years and older: complications and predictive factors. J Neurosurg Spine 15:667-674, 2011

3. Azimi P, Benzel EC, Shahzadi S, Azhari S, Mohammadi HR: Use of artificial neural networks to predict surgical satisfaction in patients with lumbar spinal canal stenosis: clinical article. J Neurosurg Spine 20:300-305, 2014

4. Azimi P, Mohammadi HR, Benzel EC, Shahzadi S, Azhari S, Montazeri A: Artificial neural networks in neurosurgery. J Neurol Neurosurg Psychiatry 86:251-256, 2015

5. Baker GA, Cizik AM, Bransford RJ, Bellabarba C, Konodi MA, Chapman JR, et al: Risk factors for unintended durotomy during spine surgery: a multivariate analysis. Spine J 12:121-126, 2012

6. Bridwell KH, Baldus C, Berven S, Edwards C II, Glassman $\mathrm{S}$, Hamill C, et al: Changes in radiographic and clinical outcomes with primary treatment adult spinal deformity surgeries from two years to three- to five-years follow-up. Spine (Phila Pa 1976) 35:1849-1854, 2010

7. Bridwell KH, Glassman S, Horton W, Shaffrey C, Schwab F, Zebala LP, et al: Does treatment (nonoperative and operative) improve the two-year quality of life in patients with adult symptomatic lumbar scoliosis: a prospective multicenter evidence-based medicine study. Spine (Phila Pa 1976) 34:2171-2178, 2009

8. Bridwell KH, Lewis SJ, Edwards C, Lenke LG, Iffrig TM, Berra A, et al: Complications and outcomes of pedicle subtraction osteotomies for fixed sagittal imbalance. Spine (Phila Pa 1976) 28:2093-2101, 2003

9. Champain S, Benchikh K, Nogier A, Mazel C, Guise JD, Skalli W: Validation of new clinical quantitative analysis software applicable in spine orthopaedic studies. Eur Spine J 15:982-991, 2006

10. Charlson M, Szatrowski TP, Peterson J, Gold J: Validation of a combined comorbidity index. J Clin Epidemiol 47:12451251,1994

11. Charosky S, Guigui P, Blamoutier A, Roussouly P, Chopin 
D: Complications and risk factors of primary adult scoliosis surgery: a multicenter study of 306 patients. Spine (Phila Pa 1976) 37:693-700, 2012

12. Chen HN, Tsai YF: A predictive model for disability in patients with lumbar disc herniation. J Orthop Sci 18:220-229, 2013

13. Cho SK, Bridwell KH, Lenke LG, Cho W, Zebala LP, Pahys $\mathrm{JM}$, et al: Comparative analysis of clinical outcome and complications in primary versus revision adult scoliosis surgery. Spine (Phila Pa 1976) 37:393-401, 2012

14. Cizik AM, Lee MJ, Martin BI, Bransford RJ, Bellabarba C, Chapman JR, et al: Using the spine surgical invasiveness index to identify risk of surgical site infection: a multivariate analysis. J Bone Joint Surg Am 94:335-342, 2012

15. Daubs MD, Hung M, Adams JR, Patel AA, Lawrence BD, Neese AM, et al: Clinical predictors of psychological distress in patients presenting for evaluation of a spinal disorder. Spine J 14:1978-1983, 2014

16. Daubs MD, Lenke LG, Cheh G, Stobbs G, Bridwell KH: Adult spinal deformity surgery: complications and outcomes in patients over age 60. Spine (Phila Pa 1976) 32:22382244, 2007

17. DeWald CJ, Stanley T: Instrumentation-related complications of multilevel fusions for adult spinal deformity patients over age 65: surgical considerations and treatment options in patients with poor bone quality. Spine (Phila Pa 1976) 31 (19 Suppl):S144-S151, 2006

18. Glassman SD, Hamill CL, Bridwell KH, Schwab FJ, Dimar JR, Lowe TG: The impact of perioperative complications on clinical outcome in adult deformity surgery. Spine (Phila Pa 1976) 32:2764-2770, 2007

19. Guyot JP, Cizik A, Bransford R, Bellabarba C, Lee MJ: Risk factors for cardiac complications after spine surgery. Evid Based Spine Care J 1:18-25, 2010

20. Hassanzadeh H, Jain A, El Dafrawy MH, Ain MC, Mesfin A, Skolasky RL, et al: Three-column osteotomies in the treatment of spinal deformity in adult patients 60 years old and older: outcome and complications. Spine (Phila Pa 1976) 38:726-731, 2013

21. Ialenti MN, Lonner BS, Verma K, Dean L, Valdevit A, Errico T: Predicting operative blood loss during spinal fusion for adolescent idiopathic scoliosis. J Pediatr Orthop 33:372376, 2013

22. Imposti F, Cizik A, Bransford R, Bellabarba C, Lee MJ: Risk factors for pulmonary complications after spine surgery. Evid Based Spine Care J 1:26-33, 2010

23. Kim YJ, Bridwell KH, Lenke LG, Cheh G, Baldus C: Results of lumbar pedicle subtraction osteotomies for fixed sagittal imbalance: a minimum 5-year follow-up study. Spine (Phila Pa 1976) 32:2189-2197, 2007

24. Lee MJ, Cizik AM, Hamilton D, Chapman JR: Predicting medical complications after spine surgery: a validated model using a prospective surgical registry. Spine J 14:291-299, 2014

25. Lee MJ, Hacquebord J, Varshney A, Cizik AM, Bransford RJ, Bellabarba C, et al: Risk factors for medical complication after lumbar spine surgery: a multivariate analysis of 767 patients. Spine (Phila Pa 1976) 36:1801-1806, 2011

26. Lee MJ, Konodi MA, Cizik AM, Bransford RJ, Bellabarba C, Chapman JR: Risk factors for medical complication after spine surgery: a multivariate analysis of 1,591 patients. Spine J 12:197-206, 2012

27. Li G, Passias P, Kozanek M, Fu E, Wang S, Xia Q, et al: Adult scoliosis in patients over sixty-five years of age: outcomes of operative versus nonoperative treatment at a minimum two-year follow-up. Spine (Phila Pa 1976) 34:21652170, 2009

28. Liu S, Schwab F, Smith JS, Klineberg E, Ames CP, Mundis $\mathrm{G}$, et al: Likelihood of reaching minimal clinically important difference in adult spinal deformity: a comparison of operative and nonoperative treatment. Ochsner J 14:67-77, 2014

29. Mathai KM, Kang JD, Donaldson WF, Lee JY, Buffington $\mathrm{CW}$ : Prediction of blood loss during surgery on the lumbar spine with the patient supported prone on the Jackson table. Spine J 12:1103-1110, 2012

30. Norton RP, Bianco K, Lafage V, Schwab FJ: Complications and intercenter variability of three-column resection osteotomies for spinal deformity surgery: a retrospective review of 423 patients. Evid Based Spine Care J 4:157-159, 2013

31. O'Brien MF, Kuklo TR, Blanke K, Lenke L (eds): Spinal Deformity Study Group Radiographic Measurement Manual. Memphis: Medtronic Sofamor Danek, 2005

32. Osorio JA, Scheer JK, Ames CP: Predictive modeling of complications. Curr Rev Musculoskelet Med 9:333-337, 2016

33. Rillardon L, Levassor N, Guigui P, Wodecki P, Cardinne L, Templier A, et al: [Validation of a tool to measure pelvic and spinal parameters of sagittal balance.] Rev Chir Orthop Reparatrice Appar Mot 89:218-227, 2003 (Fr)

34. Scheer JK, Smith JS, Clark AJ, Lafage V, Kim HJ, Rolston JD, et al: Comprehensive study of back and leg pain improvements after adult spinal deformity surgery: analysis of 421 patients with 2-year follow-up and of the impact of the surgery on treatment satisfaction. J Neurosurg Spine 22:540553,2015

35. Schwab F, Ungar B, Blondel B, Buchowski J, Coe J, Deinlein D, et al: Scoliosis Research Society-Schwab adult spinal deformity classification: a validation study. Spine (Phila Pa 1976) 37:1077-1082, 2012

36. Smith JS, Kasliwal MK, Crawford A, Shaffrey CI: Outcomes, expectations, and complications overview for the surgical treatment of adult and pediatric spinal deformity. Spine Deform [epub ahead of print], 2012

37. Smith JS, Klineberg E, Schwab F, Shaffrey CI, Moal B, Ames CP, et al: Change in classification grade by the SRSSchwab Adult Spinal Deformity Classification predicts impact on health-related quality of life measures: prospective analysis of operative and nonoperative treatment. Spine (Phila Pa 1976) 38:1663-1671, 2013

38. Smith JS, Lafage V, Shaffrey CI, Schwab F, Lafage R, Hostin $\mathrm{R}$, et al: Outcomes of operative and nonoperative treatment for adult spinal deformity: a prospective, multicenter matched cohort assessment with 2-year follow-up. Neurosurgery 78:851-861, 2016

39. Smith JS, Sansur CA, Donaldson WF III, Perra JH, Mudiyam R, Choma TJ, et al: Short-term morbidity and mortality associated with correction of thoracolumbar fixed sagittal plane deformity: a report from the Scoliosis Research Society Morbidity and Mortality Committee. Spine (Phila Pa 1976) 36:958-964, 2011

40. Smith JS, Shaffrey CI, Berven S, Glassman S, Hamill C, Horton W, et al: Improvement of back pain with operative and nonoperative treatment in adults with scoliosis. Neurosurgery 65:86-94, 2009

41. Smith JS, Shaffrey CI, Berven S, Glassman S, Hamill C, Horton W, et al: Operative versus nonoperative treatment of leg pain in adults with scoliosis: a retrospective review of a prospective multicenter database with two-year follow-up. Spine (Phila Pa 1976) 34:1693-1698, 2009

42. Smith JS, Shaffrey CI, Glassman SD, Berven SH, Schwab FJ, Hamill CL, et al: Risk-benefit assessment of surgery for adult scoliosis: an analysis based on patient age. Spine (Phila Pa 1976) 36:817-824, 2011

43. Smith JS, Shaffrey CI, Glassman SD, Carreon LY, Schwab FJ, Lafage V, et al: Clinical and radiographic parameters that distinguish between the best and worst outcomes of scoliosis surgery for adults. Eur Spine J 22:402-410, 2013

44. Smith JS, Shaffrey CI, Lafage V, Schwab F, Scheer JK, Pro- 
topsaltis T, et al: Comparison of best versus worst clinical outcomes for adult spinal deformity surgery: a retrospective review of a prospectively collected, multicenter database with 2-year follow-up. J Neurosurg Spine 23:349-359, 2015

45. Smith JS, Singh M, Klineberg E, Shaffrey C, Lafage V, Schwab FJ, et al: Surgical treatment of pathological loss of lumbar lordosis (flatback) in patients with normal sagittal vertical axis achieves similar clinical improvement as surgical treatment of elevated sagittal vertical axis. J Neurosurg Spine 21:160-170, 2014

46. Tetreault LA, Kopjar B, Vaccaro A, Yoon ST, Arnold PM, Massicotte EM, et al: A clinical prediction model to determine outcomes in patients with cervical spondylotic myelopathy undergoing surgical treatment: data from the prospective, multi-center AOSpine North America study. J Bone Joint Surg Am 95:1659-1666, 2013

47. Weiss HR, Goodall D: Rate of complications in scoliosis surgery-a systematic review of the Pub Med literature. Scoliosis 3:9, 2008

48. Yadla S, Maltenfort MG, Ratliff JK, Harrop JS: Adult scoliosis surgery outcomes: a systematic review. Neurosurg Focus 28(3):E3, 2010

49. Yang BP, Ondra SL, Chen LA, Jung HS, Koski TR, Salehi SA: Clinical and radiographic outcomes of thoracic and lumbar pedicle subtraction osteotomy for fixed sagittal imbalance. J Neurosurg Spine 5:9-17, 2006

50. Zhang HQ, Huang J, Guo CF, Liu SH, Tang MX: Two-level pedicle subtraction osteotomy for severe thoracolumbar kyphotic deformity in ankylosing spondylitis. Eur Spine J 23:234-241, 2014

\section{Disclosures}

The International Spine Study Group Foundation (ISSGF), through which this study was conducted, is funded through research grants from DePuy Spine, Innovasis, Biomet, K2, NuVasive, and individual donations. Dr. Smith has served as a consultant to Zimmer Biomet, NuVasive, and Cerapedics; has received royalties from Zimmer Biomet; has received support of non-study-related clinical or research effort from DePuy Synthes; has received clinical or research support for the study described from DePuy Synthes; and has received fellowship support from AOSpine and the NREF. Dr. Schwab has direct stock ownership in Nemaris Inc.; has served as a consultant to Zimmer Biomet, K2M, MSD, Medicrea, and NuVasive; has received support of non-study-related clinical or research effort from SRS, AO, and DePuy Synthes (paid through ISSGF); is a patent holder for MSD and K2M; and has speaking/teaching arrangements with Zimmer Biomet, K2M, MSD, Medicrea, and NuVasive. Dr. Lafage has direct stock ownership in Nemaris Inc.; has served as a consultant to NuVasive; has speaking/teaching arrangements with NuVasive, Medicrea, DePuy Spine, and Nemaris Inc.; and has received support of non-study-related clinical or research effort from SRS, NIH, and DePuy Spine (paid through ISSGF). Dr. Shaffrey has served as a consultant to Medtronic, NuVasive, Zimmer Biomet, $\mathrm{K} 2 \mathrm{M}$, and Stryker; has direct stock ownership in NuVasive; is a patent holder for Medtronic, NuVasive, and Zimmer Biomet; and has received support of non-study-related clinical or research effort from DePuy Synthes. Dr. Bess has served as a consultant to NuVasive, K2 Medical, and Allosource; is a patent holder for Innovasis and K2 Medical; has received clinical or research support for this study from DePuy Spine; and has received support of non-study-related clinical or research effort from Medtronic, K2 Medical, Innovasis, and Stryker. Dr. Daniels has served as a consultant to Stryker, Globus, DePuy, and Orthofix; and has received support of non-study-related clinical or research effort from Orthofix. Dr. Hart has served as a consultant to DePuy Synthes and Globus; is a patent holder for Oregon Health \& Science University; and has received royalties and/or paid honoraria from SeaSpine, DePuy Synthes, and Globus. Dr. Protopsaltis has served as a consultant to Medicrea International, Globus, and Innovasis; and has received clinical or research support for this study from Zimmer Spine. Dr. Mundis Jr. has served as a consultant to NuVasive, K2M, and DePuy Synthes. Dr. Sciubba has served as a consultant to Medtronic, DePuy Synthes, Orthofix, Globus, and Stryker. Dr. Burton has served as a consultant to DePuy Spine, and has received clinical or research support for this study from DePuy Spine. Dr. Klineberg has served as a consultant to DePuy and Stryker, and has received a fellowship grant and honoraria from AOSpine, and honoraria from K2M. Dr. Ames has served as a consultant to DePuy, Stryker, and Medtronic; is a patent holder for Fish \& Richardson, PC; and has received royalties from Stryker and Biomet Spine.

\section{Author Contributions}

Conception and design: Scheer, Ames. Acquisition of data: Lafage. Analysis and interpretation of data: Scheer. Drafting the article: Scheer. Critically revising the article: Scheer, Smith, Schwab, Daniels, Protopsaltis, Ailon, Burton, Ames. Reviewed submitted version of manuscript: all authors. Approved the final version of the manuscript on behalf of all authors: Scheer. Statistical analysis: Scheer. Study supervision: Ames.

\section{Correspondence}

Justin K. Scheer, School of Medicine, University of California, San Diego, 9500 Gilman Dr., La Jolla, CA 92093. email: jscheer@uic.edu. 